\title{
COUPLED PROBLEMS OF INTERACTION OF DEFORMABLE BODIES AND LIQUID OF HIGH PRESSURE
}

\begin{abstract}
Nowadays the problems of interaction between solids and liquid under high and extremely high pressure are fairly relevant. So the main aim of presented research work is: creating the mathematical models and methods to investigate the interaction of bodies that include cracks filled with a compressible liquid or gas. The coupled problem of interaction of nonlinear elastic bodies and liquid of high pressure was considered. The pressure exerted by a liquid or gas present in the cavities of solids depends on the deformation of the body. In turn the deformation is caused by the pressure inside the cavity. The interaction between a deformable body and liquid is presented as a variational problem. The iterative splitting process of the coupled problem was proposed as well as the algorithm of numerical solution based on variational approach and finite element method. The software which allows calculating the stress state of an elastic body for some classes of problems was developed basing on the algorithm of splitting. The plane problem with cavity and solid stamp which imposes pressure on the boundary was considered and the numerical solution was computed using created software.
\end{abstract}

Keywords: elastic body, compressible liquid, plane deformation, variational problems, iterative process of splitting

\section{ZAGADNIENIA INTERAKCJI CIAŁ STAEYCH I CIECZY POD WYSOKIM CIŚNIENIEM}

Problem interakcji ciat statych i cieczy znajdujacych sie pod wysokim lub ekstremalnie wysokim ciśnieniem wzbudza obecnie zainteresowanie. Gtównymi celami zaprezentowanych badań jest stworzenie modelu matematycznego i metod badania ciat, które zawieraja rysy wypetnione ściśliwq ciecza lub gazem. Przeanalizowano sprzeżony problem interakcji nieliniowo spreżystych ciat i ptynu pod wysokim ciśnieniem. Ciśnienie cieczy lub gazu w kawernie ciała stałego zależy od deformacji ciata. Z kolei deformacja ta zależy od ciśnienia $w$ kawernie. Sformułowany zostat wariacyjny problem interakcji ciała stałego i ptynu. Zaproponowano iteracyjny rozkład problemu sprzeżonego i algorytm rozwiazania numerycznego, oparty na podejściu wariacyjnym i metodzie elementów skończonych. Na podstawie tego algorytmu opracowano oprogramowanie, które pozwala na obliczenie stanu naprezzenia w ciele sprężystym dla określonej klasy problemów. Dokonano analizy płaskiego problemu ciała z kawernq i stemplem ściskajacym i przedstawiono wyniki rozwiazania numerycznego uzyskanego stworzonym programem.

Stowa kluczowe: ciało spręzyste, ciecz ściśliwa, deformacja płaska, problem wariacyjny, iteracyjny proces dekompozycji

\section{INTRODUCTION}

The study of interaction of deformable bodies with high pressure liquid is associated with a number of engineering and technological problems in various fields of engineering. Let us mention some of them.

In production processes of hydroextrusion the deformation of the workpiece is carried out using liquid of high pressure (fig. 1), the object of study is as a process of deformation as well as strength of technological equipment. Liquid and gaseous mineral resources located in earth crust usually are under considerable pressure (fig. 2). The processes of extraction of petroleum and gas should take into account the impact of high-of pressure on crustal deformation (Shumelchyk and Kuzmenko 2013).

Let also note the necessity to study the impact of lubricants on the work of load friction units. A typical feature of the mentioned processes is a significant pressure of a liquid that is reaching tens of thousands of atmospheres. The phenomenon of 'popping' workpiece and origination a gusher indicates that there is substantial accumulation of potential energy of compressed liquid.

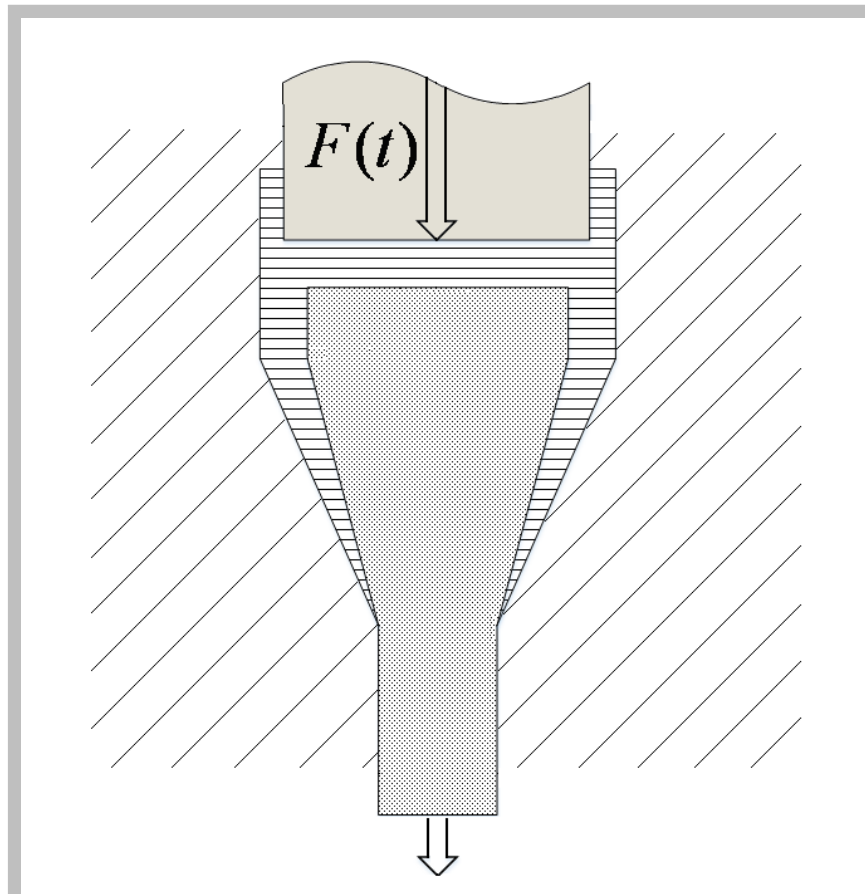

Fig. 1. Hydroextrusion process

\footnotetext{
* Oles Honchar Dnipropetrovsk National University, Chair of Mathematical Modeling, Applied Mathematics Department, Dnipropetrovsk, Ukraine; shumelchyk@gmail.com
} 


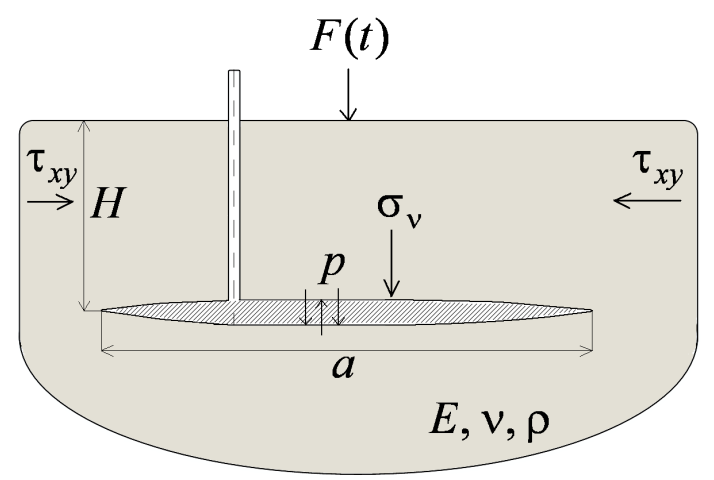

Fig. 2. Location of liquid minerals in earth crust

The traditional assumption of liquid's incompressibility excludes the possibility of taking into account the potential energy of the liquid. Therefore, at modeling of deformable bodies and liquid, last one should be considered as compressible. For most of actual liquids the density depends on the pressure and in the case of large values of pressure is nonlinear. Finally, the mathematical model must take into account the linked character of interaction between liquid and body when liquid's pressure causes a change in the stress state and vice versa the deformation of solids affects the change of pressure in the liquid. The problem of hydraulic fractures propagating near free surface is considered in recent work (Bunger $e t$ al. 2013).

Modeling of saucer-shaped hydraulic fractures poses challenges that include the need to track the evolution of the crack path and follow two distinct moving boundaries corresponding to the leading edge of the crack and fluid front. As result of research two important results were obtained: one is series of near-surface hydraulic fracturing experiments and other is implementation of numerical algorithm OribiC, capable of simulating the growth of a saucer-shaped hydraulic fracture in elastic body. The results can be applied in modeling natural rock masses, but proposed model does not include such processes as compressibility of the liquid and non-linear dependencies in it.

Analysis of contact interaction taking into account the influence of a substance that fills the intercontact gap is described in works (Chumak 2011, Uralsky and Plakhotin 1978). In these studies the relationship between pressure and density the substance in gap is considered as linear, which allows reducing the problem to solving integral equations. In research work these assumptions are not used, so the solution is based on numerical methods.

Influence of local intercontact gaps filled with gas or liquid at the contact behavior of bodies with surface grooves in the conditions of plane deformation was studied in (Martynyak and Slobodyan 2008, 2009). The contact of elastic half-spaces with compressible liquid inside an elliptic intercontact gap is considered. The formulated problem is reduced to an analytically solved integro-differential equation with respect to the gap height.

Research work aims to build a mathematical model of interaction a nonlinear elastic body with a liquid that is under considerable high pressure, to develop the numerical methods for solving the problem and to analyze the characteristics of coupled deformation of elastic body and liquid.

The peculiarity of the work is based on taking into account the nonlinearity and compressibility of liquid as well as the construction and justification of iterative algorithm.

\section{PROBLEM STATEMENT}

The process of coupled deformation of nonlinear elastic bodies and compressible liquid is considered (fig. 3). In unstrained state the bodies occupy regions $\Omega_{1}$ and $\Omega_{2}$, and liquid occupies region $\Omega_{0}$.

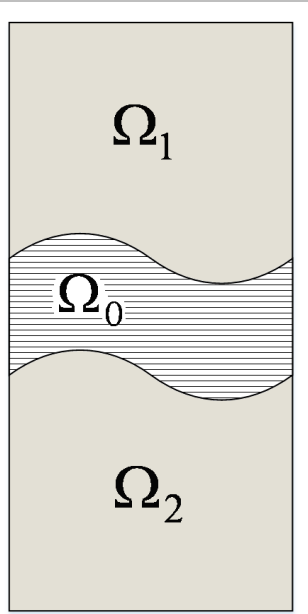

Fig. 3. Interaction between nonlinear elastic bodies and compressible liquid

We denote by $\Omega$ common region of deformable bodies and fluid:

$$
\Omega=\Omega_{0} \cup \Omega_{1} \cup \Omega_{2}
$$

Let us introduce the Cartesian coordinate system $O x_{1} x_{2} x_{3}$ and denote by $\bar{x}=\left(x_{1}, x_{2}, x_{3}\right)$ the radius vector of an arbitrary point of region $\Omega$. Let $u_{i}(\bar{x}), \varepsilon_{i j}(\bar{x}), \sigma_{i j}(\bar{x})$ be the components of displacement vector $\bar{u}$, strain tensor $\hat{\varepsilon}$ and the stress tensor $\hat{\sigma}$ at a point $\bar{x} \in \Omega$. The components of stress tensor satisfy the equation of equilibrium:

$$
\sigma_{i j, j}=0, \forall x \in \Omega
$$

and the components of strain tensor are connected with displacements by the Cauchy relation:

$$
\varepsilon_{i j}(\bar{x})=\frac{1}{2}\left[u_{i, j}(\bar{x})+u_{j, i}(\bar{x})\right]
$$

For determining characteristic of deformable bodies we select the properties of physical nonlinear elasticity:

$$
\begin{aligned}
& \sigma_{i j}=\varphi_{i j}^{1}(\hat{\varepsilon})-\text { in region } \Omega_{1} \\
& \sigma_{i j}=\varphi_{i j}^{2}(\hat{\varepsilon})-\text { in region } \Omega_{2}
\end{aligned}
$$

Relations in such form are also used in the deformation theory of plasticity with the active load. The liquid is considered ideal and compressible. The mechanical properties of 
this liquid are described by defining relations that link the average hydrostatic pressure:

$$
\sigma=\frac{1}{3} \sigma_{i j} \delta_{i j}
$$

and average deformation:

$$
\varepsilon=\frac{1}{3} \varepsilon_{i j} \delta_{i j}
$$

therefore:

$$
\sigma=\varphi^{(o)}(\varepsilon)
$$

In order to unify described formulas let us give this dependence in the following form:

$$
\sigma_{i j}=\varphi_{0}(\varepsilon) \delta_{i j}
$$

Let us formulate boundary conditions. Surfaces $\Gamma_{1}$ and $\Gamma_{2}$ of areas $\Omega_{1}$ and $\Omega_{2}$ could be represented in the following form:

$$
\begin{aligned}
& \Gamma_{1}=\Gamma_{1}^{u} \cup \Gamma_{1}^{\sigma} \cup \Gamma_{1}^{c}, \\
& \Gamma_{2}=\Gamma_{2}^{u} \cup \Gamma_{2}^{\sigma} \cup \Gamma_{2}^{c} .
\end{aligned}
$$

On the surfaces $\Gamma_{1}^{u}$ and $\Gamma_{2}^{u}$ displacements are set:

$$
\bar{u}(\bar{x})=\bar{U}(\bar{x}), \forall x \in \Gamma_{1}^{u} \cup \Gamma_{2}^{u}
$$

and on the surfaces $\Gamma_{1}^{\sigma}$ and $\Gamma_{2}^{\sigma}$ stresses are set:

$$
\bar{\sigma}_{i j}(\bar{x}) v_{j}(\bar{x})=S_{i}(\bar{x}), \forall \bar{x} \in \Gamma_{1}^{\sigma} \cup \Gamma_{2}^{\sigma}
$$

Components of the unit outer normal vector $\bar{v}(\bar{x})$ to the surface area are naturally denoted by $v_{i}(\bar{x})$.

Deformable bodies interact with the liquid only on surfaces $\Gamma_{1}^{c}$ and $\Gamma_{2}^{c}$. Let us decompose vectors of displacements and stresses at the points of the surfaces $\Gamma_{1}^{c}$ and $\Gamma_{2}^{c}$ to normal and tangential components:

$$
\begin{aligned}
& u_{v}(\bar{x})=\bar{u}(x) \bar{v}(x) ; \bar{u}_{v}(\bar{x})=u_{\vee}(\bar{x}) \bar{v}(x) ; \\
& \bar{u}_{\tau}(\bar{x})=u(\bar{x})-\bar{u}_{v}(\bar{x}) \\
& \sigma_{v}(\bar{x})=\sigma_{i j}(x) v_{i}(\bar{x}) v_{j}(\bar{x}) ; \\
& \bar{\sigma}_{v}(\bar{x})=\sigma_{v}(\bar{x}) \bar{v}(x) \\
& \left(\bar{\sigma}_{\tau}(\bar{x})\right)_{i}=\sigma_{i j}(x) v_{j}(\bar{x})-\sigma_{v}(\bar{x}) \bar{v}_{i}
\end{aligned}
$$

We consider that after crossing common boundary of deformable bodies and liquid the normal components of the displacement and stress vectors still are continuous.

Deformation process is considered as quasistatic, so the viscosity of liquid will not be taken into account, i.e.

$$
\bar{\sigma}_{\tau}(\bar{x})=\overline{0}, \forall \bar{x} \in \Gamma_{1}^{c} \cup \Gamma_{2}^{c}
$$

So the formulated problem has to determine the vector of displacements $\bar{u}(\bar{x})$, strain tensor $\hat{\varepsilon}(\bar{x})$ and stress tensor $\hat{\sigma}(\bar{x})$ in area $\Omega$ that satisfy the equation of equilibrium (1), defining relations (3)-(5), the Cauchy relation (2), the boundary conditions (6)-(7) and the conditions of interaction between deformable bodies and liquid (8)-(10).

\section{VARIATIONAL FORMULATION OF THE PROBLEM}

Representation of problem in variational formulation is taken from (Kuzmenko 1979). Let us introduce the Sobolev space:

$$
W_{2}^{(1)}(\Omega)=W_{2}^{(1)}\left(\Omega_{0}\right) \times W_{2}^{(1)}\left(\Omega_{1}\right) \times W_{2}^{(1)}\left(\Omega_{2}\right)
$$

and distinguish in this space the set $V$ of permissible displacements. Let us include in the set $V$ all vector-functions $\bar{v} \in W_{2}^{(1)}(\Omega)$ satisfying the boundary conditions for displacement (6) and the continuity conditions for normal displacement at $\Gamma_{c}$. We define the actual displacement of points in region $\Omega$ as $\bar{u} \in V$, and an arbitrary element from set $V$ as $\bar{v} \in V$.

Components of actual strain tensor and possible strain tensor components are naturally defined as $\varepsilon_{i j}(\bar{u})$ and $\xi_{i j}(\bar{v})$, which can be expressed as:

$$
\xi_{i j}(\bar{v})=\frac{1}{2}\left(v_{i, j}+v_{j, i}\right)
$$

If $\sigma_{i j}$ are the real components of the stress tensor, then:

$$
-\sigma_{i j, j}(\bar{x}) \equiv 0, \forall \bar{x} \in \Omega
$$

Both sides of the identity are multiplied by $v_{i}-u_{i}$ and then integrated in each of the regions $\Omega_{1}, \Omega_{2}, \Omega_{0}$ separately. We explain the further transformations after integration process for area $\Omega_{1}$ (for other regions the conversions would be similar). So, both sides of (11) are multiplied by $v_{i}-u_{i}$ and integrated over a region $\Omega_{1}$ :

$$
-\int_{\Omega_{1}} \sigma_{i j, j}\left(v_{i}-u_{i}\right) d \Omega=0
$$

Integrand can be represented as:

$$
\begin{aligned}
\frac{\partial}{\partial x_{j}} & {\left[\sigma_{i j}\left(v_{i}-u_{i}\right)\right]=\sigma_{i j, j}\left(v_{i}-u_{i}\right)+\sigma_{i j}\left(v_{i, j}-u_{i, j}\right)=} \\
& =\sigma_{i j, j}\left(v_{i}-u_{i}\right)+\sigma_{i j}\left[\frac{1}{2}\left(v_{i, j}+v_{j, i}\right)-\frac{1}{2}\left(u_{i, j}+u_{j, i}\right)\right]= \\
& =\sigma_{i j, j}\left(v_{i}-u_{i}\right)+\sigma_{i j}\left(\xi_{i j}-\varepsilon_{i j}\right)
\end{aligned}
$$

Then equation (12) takes the form:

$$
\int_{\Omega_{1}} \sigma_{i j}\left(\xi_{i j}-\varepsilon_{i j}\right) d \Omega-\int_{\Omega_{1}} \frac{\partial}{\partial x_{j}}\left[\sigma_{i j}\left(v_{i}-u_{i}\right)\right] d \Omega=0
$$

We can apply to the second integral a formula of GaussOstrogradskiy:

$$
\int_{\Omega_{1}} \sigma_{i j}\left(\xi_{i j}-\varepsilon_{i j}\right) d \Omega-\int_{\Gamma_{1}} \sigma_{i j} \cdot v_{j}\left(v_{i}-u_{i}\right) d \Gamma=0, \forall v \in V .
$$

Integral over $\Gamma_{1}$ can be presented as a sum of integrals over $\Gamma_{1}^{c}, \Gamma_{1}^{u}, \Gamma_{1}^{\sigma}$. Integral over $\Gamma_{1}^{u}$ equals zero as far as $\bar{u}=\bar{v}$ at $\Gamma_{1}^{u}$. Integral over $\Gamma_{1}^{\sigma}$ using the boundary conditions (7) is reduced to the integral:

$$
\int_{\Gamma_{1}} S_{i}\left(v_{i}-u_{i}\right) d \Gamma
$$


Integral over $\Gamma_{1}^{c}$ can be presented in following form:

$$
\int_{\Gamma_{1}}\left[\sigma_{v}\left(v_{v}-u_{v}\right)+\bar{\sigma}_{\tau}\left(\bar{v}_{\tau}-\bar{u}_{\tau}\right)\right] d \Gamma
$$

After execution of similar transformations for regions $\Omega_{2}$ and $\Omega_{0}$ we get two analogical integral equalities. All of three obtained equalities we add together. Please note that the integrals over $\Gamma_{1}^{c}$ and $\Gamma_{2}^{c}$ are calculated twice and have opposite signs, i.e. the sum of integrals over $\Gamma_{1}^{c}$ and sum of integrals over $\Gamma_{2}^{c}$ equals zero. As result we finally get variational equation:

$$
\begin{array}{r}
\int_{\Omega} \sigma_{i j}\left(\varepsilon_{i j}\right)\left(\xi_{i j}-\varepsilon_{i j}\right) d \Omega-\int_{\Gamma^{\sigma}} S_{i}\left(v_{i}-u_{i}\right) d \Gamma=0, \\
\forall \bar{v} \in V
\end{array}
$$

We should turn from the variational equation to the appropriate extremal problem. Let us introduce the density of deformation energy:

$$
W(\hat{\varepsilon})=\int_{0}^{\varepsilon_{i j}} \sigma_{i j}(\hat{\varepsilon}) d \varepsilon_{i j}
$$

We consider that function $W(\hat{\varepsilon})$ is positive definite. Using equality (14) stress components can be expressed in next way:

$$
\sigma_{i j}=\frac{\partial W(\hat{\varepsilon})}{\partial \varepsilon_{i j}} .
$$

Then the variational equation becomes:

$$
\int_{\Omega} \frac{\partial W(\hat{\varepsilon})}{\partial \varepsilon_{i j}}\left(\xi_{i j}-\varepsilon_{i j}\right) d \Omega-\int_{\Gamma^{\sigma}} S_{i}\left(v_{i}-u_{i}\right) d \Gamma=0,
$$

$$
\forall \bar{v} \in V
$$

For real materials and compressible liquids density of deformation energy is a convex function. Assuming that $W(\hat{\varepsilon})$ is a convex function, we can use the well-known inequality:

$$
\frac{\partial W(\hat{\varepsilon})}{\partial \varepsilon_{i j}}\left(\xi_{i j}-\varepsilon_{i j}\right) \leq W\left(\xi_{i j}\right)-W\left(\varepsilon_{i j}\right)
$$

and transform the variational equation (15) to an inequality:

$$
\begin{aligned}
\int_{\Omega} W(\hat{\varepsilon}) d \Omega-\int_{\Gamma^{\sigma}} \bar{S} \cdot \bar{u} d \Gamma & \leq \int_{\Omega} W(\hat{\xi}) d \Omega- \\
& -\int_{\Gamma^{\sigma}} \bar{S} \cdot \bar{v} d \Gamma, \forall \bar{v} \in V
\end{aligned}
$$

Let us introduce the functional

$$
I(v)=\int_{\Omega} W(\hat{\xi}) d \Omega-\int_{\Gamma^{\sigma}} \bar{S} \cdot \bar{v} d \Gamma .
$$

As far as appropriate linear forms in (16) are positive definite and symmetric, the inequality (16) means that the functional $I(\bar{v})$ reaches the smallest value over the set $V$ exactly in solution of the formulated problem. Similarly to (Kuzmenko
1979), we can prove the equivalence of variational problem solving (13) and the extremal problem

$$
\inf _{v \in V} I(v)
$$

as well as show that with additional assumption of existence the second partial derivative of the solution $\bar{u}(\bar{x})$ we get that solution of variational problem identical with the solution of problem in the original form.

\section{ALGORITHM OF NUMERICAL SOLUTION}

Let us consider the alternatives for numerical solution, based on finite elements. The obvious option is to include the splitting for region $\Omega_{0}$ occupied by the liquid in the general scheme of discretization. However, this approach is ineffective because the stress state inside liquid is homogeneous. Indeed, the equilibrium equation in region $\Omega_{0}$ is:

$$
\frac{\partial \sigma_{i j}}{\partial x_{j}}=\frac{\partial}{\partial x_{j}}\left(\sigma \delta_{i j}\right)=\frac{\partial \sigma}{\partial x_{j}} \delta_{i j}=0 ; j=1,2,3
$$

This implies that the $\sigma=$ const, and hence $\varepsilon=$ const in the region $\Omega_{0}$. Therefore, a more effective approach seems to be using the specified homogeneity of the stress state.

Function $W\left(\varepsilon_{i j}\right)$ in region $\Omega_{0}$ has form:

$$
W\left(\varepsilon_{i j}\right)=\int_{0}^{\varepsilon \delta_{i j}} \sigma(\varepsilon) \delta_{i j} d\left(\varepsilon \delta_{i j}\right) .
$$

We could apply the average value theorem and represent $W\left(\varepsilon_{i j}\right)$ in the following form:

$$
W\left(\varepsilon_{i j}\right)=\sigma_{*} \delta_{i j} \int_{0}^{\varepsilon \delta_{i j}} d\left(\varepsilon \delta_{i j}\right)=\sigma_{*} \delta_{i j} \varepsilon \delta_{i j}=3 \sigma_{*} \varepsilon
$$

where $\sigma_{*}$ - average value of $\sigma$ in sense of the average value theorem. Then

$$
\int_{\Omega_{0}} W\left(\varepsilon_{i j}\right)=\int_{\Omega_{0}} 3 \sigma_{*} \varepsilon d \Omega=3 \sigma_{*} \varepsilon V_{0},
$$

where $V_{0}$ - volume of region $\Omega_{0}$.

Note that $3 \varepsilon=\theta$ is a relative change in the volume of liquid. On the other hand $\theta=\frac{\Delta V}{V_{0}}$. Let us calculate the change in volume of the liquid $\Delta V$ as a result of deformation:

$$
\Delta V=\int_{\Gamma_{0}^{c}} u_{v} d \Gamma
$$

Then:

$$
\int_{\Omega} W_{i j}\left(\varepsilon_{i j}\right) d \Omega=\sigma_{*} \theta V_{0}=\sigma_{*} \frac{\Delta V}{V_{0}} V_{0}=\sigma_{*} \int_{\Gamma_{0}^{c}} u_{v} d \Gamma .
$$

Considering that

$$
\int_{\Gamma_{0}^{c}} u_{v} d \Gamma=-\int_{\Gamma_{1}^{c} \cup \Gamma_{2}^{c}} u_{v} d \Gamma
$$


we can reformulate the functional in following form:

$$
I_{*}\left(\bar{v}, \sigma_{*}\right)=\int_{\Omega_{1} \cup \Omega_{2}} W\left(\xi_{i j}\right) d \Omega-\sigma_{*} \int_{\Gamma_{1}^{c} \cup \Gamma_{2}^{c}} u_{v} d \Gamma-\int_{\Gamma^{\sigma}} \bar{s} \bar{v} d \Gamma
$$

Because the mentioned value $\sigma_{*}$ is actually unknown, we propose the iterative consistent process of solving problems of minimizing the functional $I_{*}\left(\bar{v}, \sigma_{*}\right)$ for fixed values of the average hydrostatic pressure $\sigma_{*}$. Initially the value $\sigma_{*}=\sigma_{*}^{(0)}$ is given and the problem of minimization the functional $I_{*}\left(\bar{v}, \sigma_{*}^{(0)}\right)$ over the set $U$ is considered. Using the obtained values of displacements we can calculate changes of the liquid volume $\Delta V^{(0)}$ and volumetric strain:

$$
\varepsilon^{(1)}=\frac{1}{3} \cdot \frac{\Delta V^{(0)}}{V_{0}} .
$$

The next approximation for the hydrostatic pressure is calculated as:

$$
\sigma_{*}=\sigma_{*}^{(1)}=\sigma\left(\varepsilon^{(1)}\right) .
$$

Then the variational problem is solved, but this time for functional $I_{*}\left(\bar{v}, \sigma_{*}^{(1)}\right)$, and the process repeats again.

In general at the $n$-th iteration the values $\varepsilon^{(n)}=\frac{1}{3} \cdot \frac{\Delta V^{(n-1)}}{V_{0}}$ and $\sigma_{*}^{(\mathrm{n})}=\sigma\left(\varepsilon^{(n)}\right)$ are calculated and following variational problem is solved for functional:

$$
I_{*}\left(\bar{v}, \sigma_{*}^{(n)}\right)=\int_{\Omega_{1} \cup \Omega_{2}} W\left(\xi_{i j}\right) d \Omega-\sigma_{*}^{(n)} \int_{\Gamma_{1}^{c} \cup \Gamma_{2}^{c}} u_{v} d \Gamma-\int_{\Gamma^{\sigma}} \overline{s v} d \Gamma
$$

Functional is considered for fixed values of $\sigma_{*}^{(\mathrm{n})}$. Since the function $W\left(\xi_{i j}\right)$ is positive definite, the functional is convex, so it reduces to finding the extreme values.

In fact, at each step of the iterative process we solve the problem of determining displacements in the region $\Omega_{1} \cup \Omega_{2}$, that is the problem of elasticity theory. The convergence conditions of the described iterative process were investigated in work (Kuzmenko, 1979).

Discretization of the variational problem of minimizing functionals $I_{*}\left(\bar{v}, \sigma_{*}^{(n)}\right)$ was carried out using the finite elements. Since this functional, in general, is not quadratic, then the usage of the necessary conditions for an extremum of discrete extremal problem does not lead to the solving the systems of linear algebraic equations.

Therefore, more suitable is the method of direct minimizing, particularly the method of local variations or generalizations of Seidel method.

\section{SOLVING A PARTICULAR PROBLEM}

Let us consider the plane deformation of an elastic body. The body has rectangular shape (fig. 4). It is considered that body has fixed bottom and the sides.

The upper part of elastic body is under the influence of heavy solid stamp. The initial displacements of the lower border of stamp are known. Inside the body there is a crack completely filled with ideal compressible liquid.
The rectangular elastic body is homogeneous. Poisson's ratio $v$ equals to 0.3 . Let the $l_{1}$ be the length of region, $l_{2}-$ length of a stamp, $l_{3}$ - height of region, $a$ - crack length, $h-$ depth of crack, $\rho$ - material density, $g$ - the gravity acceleration, $E$ - Young's modulus. The parameter $\mu$ is defined as: $\mu=\frac{E}{2(1+v)}$. Crack width is considered as constant: $\Delta=\frac{\rho \cdot g \cdot l_{1}^{2}}{\mu}$.

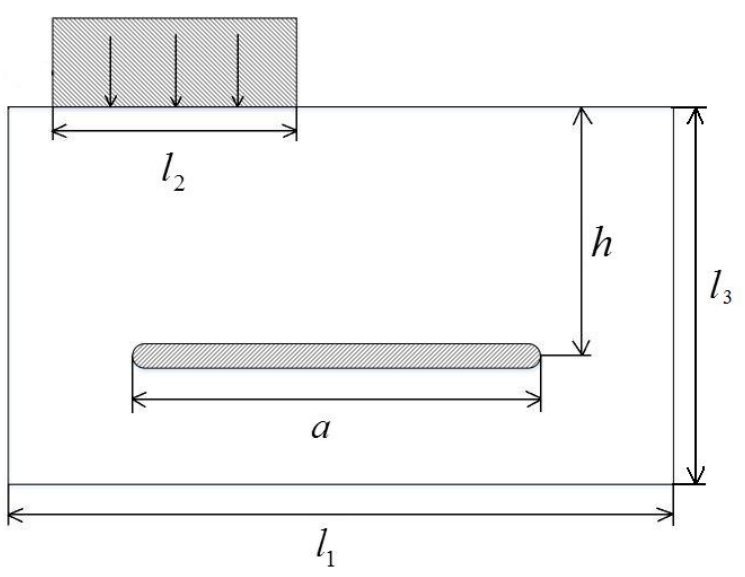

Fig. 4. Elastic body with crack under influence of heavy solid stamp

For convenience problem is presented in dimensionless form, so values of body's density and Young's modulus are used for reducing to such presentation. The crack width is also defined in a dimensionless form, and is chosen so as to better reflect the characteristics of interaction between liquid and elastic body. Calculations are performed for parameters of liquid corresponding to typical petroleum.

For given problem the functional (17) takes the form:

$$
\begin{aligned}
\Pi & =\iint_{\Omega} \frac{1}{2}\left(\lambda \theta^{2}+2 \mu \varepsilon_{i j} \varepsilon_{i j}\right) d \Omega- \\
& -\int_{\Gamma_{0}} p \Delta u_{y} d \Gamma_{0}+\iint_{\Omega} \rho g u_{y} d \Omega= \\
& =\left(\frac{1}{2} \lambda+\mu\right) \iint_{\Omega}\left[\left(\frac{\partial u_{x}}{\partial x}\right)^{2}+\left(\frac{\partial u_{y}}{\partial y}\right)^{2}\right] d \Omega+ \\
& +\frac{1}{2} \mu \iint_{\Omega}\left[\left(\frac{\partial u_{x}}{\partial y}\right)^{2}+\left(\frac{\partial u_{y}}{\partial x}\right)^{2}\right] d \Omega+ \\
& +\lambda \iint_{\Omega} \frac{\partial u_{x}}{\partial x} \cdot \frac{\partial u_{y}}{\partial y} d \Omega+\mu \iint_{\Omega} \frac{\partial u_{x}}{\partial y} \cdot \frac{\partial u_{y}}{\partial x} d \Omega- \\
& -\int_{\Gamma_{0}} p \Delta u_{y} d \Gamma_{0}+\iint_{\Omega} \rho g u_{y} d \Omega
\end{aligned}
$$

The ratio between the dimensionless and dimensional values is given by:

$$
\begin{aligned}
& x_{i}=x_{i}^{\prime} \cdot l_{1}, u_{i}=u_{i}^{\prime} \cdot \frac{\rho \cdot g \cdot l_{1}^{2}}{\mu}, \sigma_{i j}=\sigma_{i j}^{\prime} \cdot \rho \cdot g \cdot l_{1}, \\
& \varepsilon_{i j}=\varepsilon_{i j}^{\prime} \cdot \frac{\rho \cdot g \cdot l_{1}}{\mu}, \Pi=\Pi^{\prime} \cdot \frac{\rho^{2} \cdot g^{2} \cdot l_{1}^{5}}{\mu}
\end{aligned}
$$

For splitting the region we use rectangular finite elements with bilinear shape function. To solve the conditional optimization 
problem numerically we use the generalized method of over relaxation. Numerical algorithm for plane deformation problems and calculating stress state is implemented as a software product.

In order to receive solution with the acceptable accuracy the mesh with 1200 finite elements was chosen. To estimate the error of obtained results Clapeyron theorem was used. Basing on this theorem we can calculate the difference between the values of deformation energy on obtained displacements and half the work of external forces. The ratio of the difference value to the total energy value must be less than permissible error (for 1200 elements the error in value of total energy does not exceed $5 \%$ ). We found that with increasing number of elements, the values of doubled potential energy and half of the work energy are converge to the same value.

Let us show the influence of stamp on the stress state of the body. Figures reffig:kuzmenko5, show the deformed finiteelement mesh for an elastic body with crack at different depths. Depth $h$ is chosen as $0.4 \cdot l_{3}$. The displacements enlarged in $0.25 \cdot l_{1}$ times.

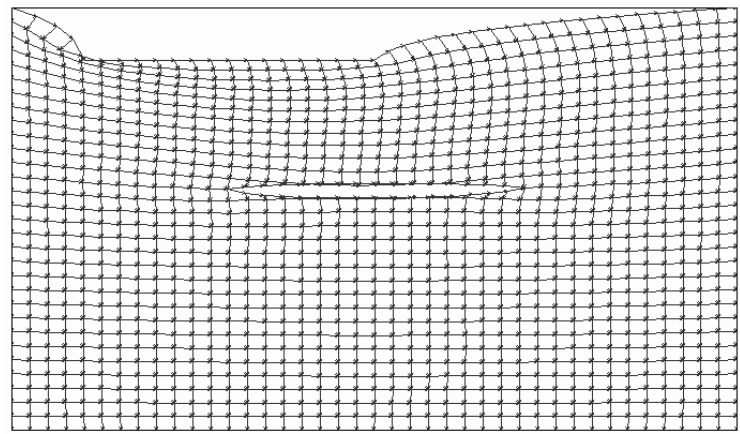

Fig. 5. Deformed finite elements mesh for elastic body with crack at depth $h$

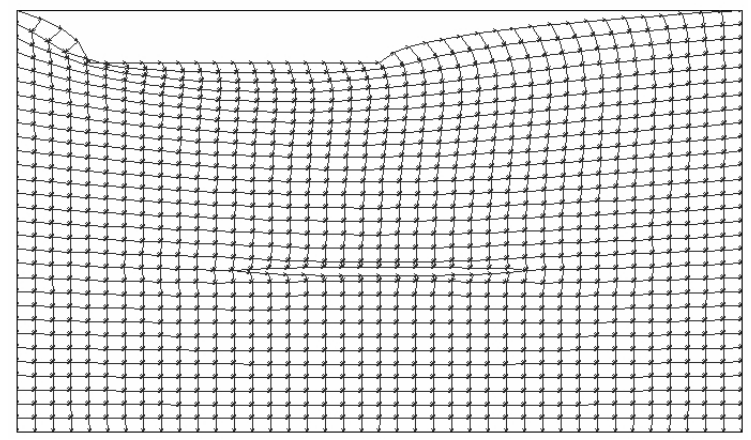

Fig. 6. Deformed finite elements mesh for elastic body with crack at depth $1.5 \mathrm{~h}$

Let us explore the stress distribution around cracks and under the surface of a stamp, depending on the depth of the crack. Figures 7-11 show the stress distribution on the surface and cracks under solid stamp.

Increasing the depth of the crack leads to changes in the distribution of contact stress $\sigma_{y}$ on the crack boundary. There

are tensile stresses, which can lead to increasing of crack. A value of stresses at left edge of crack inversely depends on its depth and is a little bit bigger than value at right edge. On the other hand, increasing depth of the crack does not lead to qualitative changes in the stress distribution under heavy solid stamp.

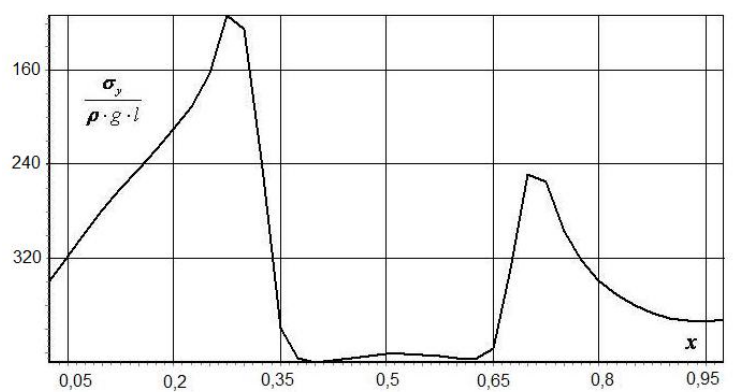

Fig. 7. Stress distribution $\sigma_{y}$ through the cavity at depth $h$

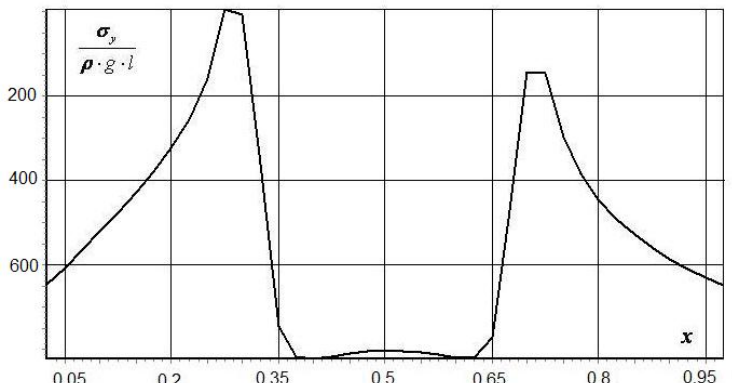

Fig. 8. Stress distribution $\sigma_{y}$ through the cavity at depth $1.5 \mathrm{~h}$

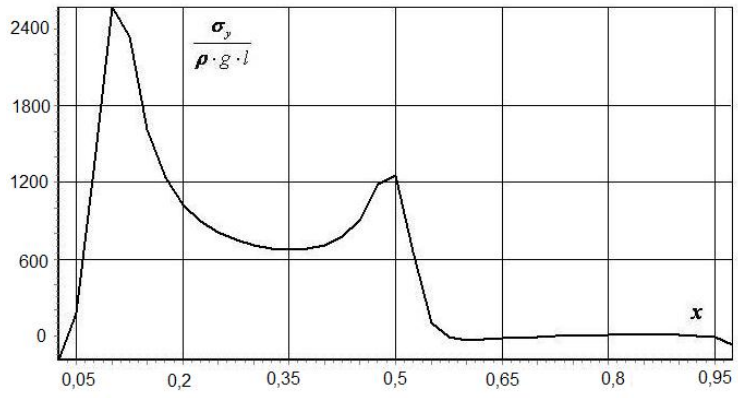

Fig. 9. Stress distribution $\sigma_{y}$ under solid stamp with crack at depth $h$

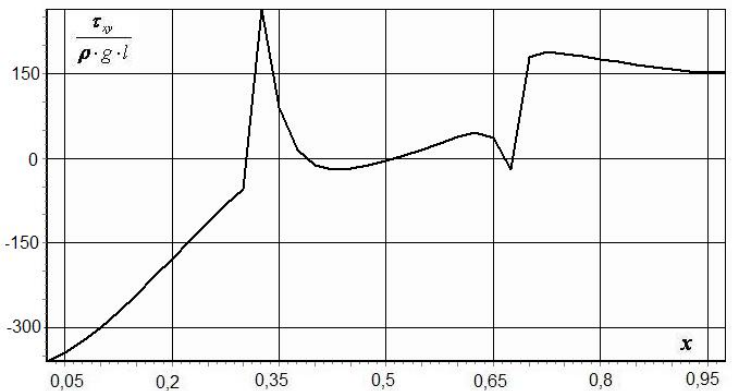

Fig. 10. Stress distribution $\tau_{x y}$ through the cavity at depth $h$ 


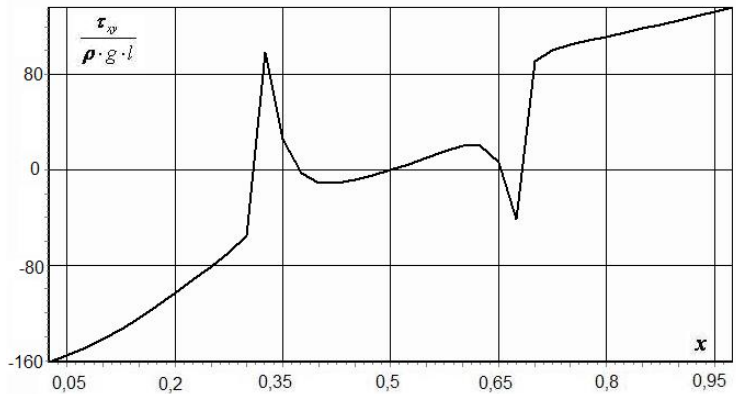

Fig. 11. Stress distribution $\tau_{x y}$ through the cavity at depth $1.5 \mathrm{~h}$

\section{CONCLUSION}

In the study we presented a formulation of the problem of the interaction between an elastic body with a compressible liquid under high pressure. Problem is formulated as the variational problem and reduced to the searching minimum of the functional in Sobolev space. The methodology of splitting the problem into separate problems for an elastic body and liquid was proposed and justified. The algorithm of numerical solving of the problem was developed and basing on it we created software that allows calculating the deformations and stress state for some classes of problems of interaction between an elastic body and a compressible liquid.
The suggested approach to study the interaction of an elastic body and liquid opens up the possibility of mathematical modelling of rock masses around the fields of liquid and gaseous mineral resources.

\section{References}

Bunger A., Gordeliy E., Detournay E. 2013, Comparison between laboratory experiments and coupled simulations of saucer-shaped hydraulic fractures in homogeneous brittle-elastic solids. J. Mech. and Physics of Solids, Series 61, No.7, pp. 1636-1654.

Chumak K. 2011, Plane thermoelastic contact problems for semispace with surface roughness and thermal resistance. Abstract of Dissertation Thesis, Pidstryhach Institute for Applied Problems of Mechanics and Mathematics, NASU. Lviv, Ukraine.

Kuzmenko V. 1979, A variational approach in the theory of contact problems for nonlinear elastic layered bodies. Applied Mathematics and Mechanics, Series 43, No. 3, pp. 893-901.

Martynyak R., Slobodyan B. 2008, Influence of Liquid Bridges in the Interface Gap on the Contact of Bodies Made of Compliant Materials. Materials Science, Series 44, No. 2, pp. 147-156.

Martynyak R., Slobodyan B. 2009, Contact of elastic half-spaces in the presence between them an elliptical gap filled with liquid. Materials Science, Series 45, No. 1, pp. 62-66.

Shumelchyk K., Kuzmenko V. 2013, Deformation of elastic body with cracks filled with a compressible liquid in a gravitational forces field. Vistnik of Oles Honchar Dnipropetrovsk National University, Mech. Series 17, Vol. 2, pp. 168-176.

Uralsky V., Plakhotin B. 1978, Production of profile shapes by hydroextrusion. Metallurgy, Moscow. 